

\title{
Anti-diabetic Activity of Roots of Ventilago calyculata Tul. in Alloxan Induced Diabetic Rats
}

\author{
N. BALAKRISHNAN ${ }^{*}$ and BHEEM Singh
}

Department of Pharmacognosy, Technocrats Institute of Technology-Pharmacy, Anand Nagar, Bhopal-462 021, India

*Corresponding author: E-mail: pharmacobala@gmail.com

(Received: 4 January 2012;

Accepted: 7 November 2012)

AJC-12376

The purpose of this study was to investigate the antidiabetic potential of the aqueous extracts of roots of Ventilago calyculata Tul. (VCAE)
and ethanol extracts of roots of Ventilago calyculata Tul. (VCEE) in the alloxan included diabetic rats. Both extracts of Ventilago calyculata
produced a significant antidiabetic activity at dose levels 200 and $400 \mathrm{mg} / \mathrm{kg}$, body weight. Concurrent histological studies of the pancreas
of these animals showed comparable regeneration by VCAE and VCEE, which were earlier, necrosed by alloxan.
Key Words: Ventilago calyculata, Alloxan, Diabetes mellitus, Blood glucose.

\section{INTRODUCTION}

Diabetes mellitus is a chronic disease caused by inherited and/or acquired deficiency in production of insulin by the pancreas, or by the ineffectiveness of the insulin produced. Such a deficiency results in increased concentrations of glucose in the blood, which in turn damage many of the body's systems, in particular the blood vessels and nerves ${ }^{1}$. As the number of people with diabetes multiplies worldwide, the disease takes an ever increasing proportion of national and international health care budgets. It is projected to become one of the world's main disablers and killers within the next 25 years. Regions with greatest potential are Asia and Africa, where diabetes mellitus rates could rise to two to three-folds than the present rates ${ }^{1}$. Apart from currently available therapeutic options, many herbal medicines have been recommended for the treatment of diabetes. Traditional plant medicines are used throughout the world for a range of diabetic presentations. The plant Ventilago calyculata Tul. (Rhamnaceae) is a large evergreen climber found throughout the hotter parts of India. It is climbing shrubs or lianas on the trees ${ }^{2}$. Tribal's of Bhopal and Betul districts of Madhya Pradesh used decoction of roots of Ventilago calyculata for the management of diabetes. However, there is no scientific evidence to support this claim. Hence, the objective of the present study is to ascertain the scientific basis for the use of Ventilago calyculata in the management of diabetes using alloxan induced diabetic rats.

\section{EXPERIMENTAL}

The roots of Ventilago calyculata were collected from during November 2010 from Bhopal, Madhya Pradesh,
India and authenticated by Department of Botany, Safias College of Science, Bhopal, India. A voucher specimen (258Bot-Safia-11) was deposited in Department of Pharmacognosy, Technocrats Institute of Technology-Pharmacy, Bhopal, India.

Experimental animals: Healthy Wistar Albino rats of either sex, weighing about 150-200 g were used for the study. All processes were approved by the Institutional animal ethical committee, which is certified by the committee for the purpose of control and supervision of experiments on animals (CPCSEA), India (Reg. No TIT/IAEC/831/P'cog//2011/12). The animals were kept in clean and dry polycarbonate cages and maintained in a well ventilated animal house with $12 \mathrm{~h}$ light- $12 \mathrm{~h}$ dark cycle. The animals were fed with standard pellet diet and water was given as libitum. For experimental purpose, the animals were kept fasting overnight but allowed for access to water.

Alloxan was obtained from SD fine chemicals limited, Mumbai. Glibenclamide was purchased from Aventis Pharmaceuticals Limited, Goa. All solvents used were of analytical grade obtained from E. Merck, Mumbai, India.

Preparation of extracts: The shade dried powdered leaves were subjected to successive extraction using pet. ether, chloroform, ethyl acetate and ethanol by continuous percolation process in soxhlet apparatus. The aqueous extract was prepared by the maceration with water. Each extract was concentrated by distilling off the solvent and evaporated to dryness. The extracts were dissolved in $1 \%$ carboxy methyl cellulose and used for the present study.

Acute toxicity study: Acute oral toxicity study ${ }^{3}$ was carried out for ethanol and aqueous extracts using acute toxic class method described as per OECD guidelines- 423 . 


\begin{tabular}{|c|c|c|c|c|}
\hline \multirow{3}{*}{ Group/Treatment (mg/kg) } & \multicolumn{4}{|c|}{$\begin{array}{l}\text { TABLE-1 } \\
\text { YCEMIC EFFECT OF AQUEOUS AND ETHANOL EXTRACTS OF ROOTS OF } \\
\text { Ventilago calyculata Tul. ON FASTING BLOOD GLUCOSE LEVEL }\end{array}$} \\
\hline & \multicolumn{4}{|c|}{ Blood glucose levels (mg/dL) } \\
\hline & $0 \mathrm{~min}$ & $30 \mathrm{~min}$ & $60 \mathrm{~min}$ & $120 \mathrm{~min}$ \\
\hline Normal control & $90.6 \pm 4.0$ & $92.0 \pm 2.4$ & $96.8 \pm 2.6$ & $92.0 \pm 2.0$ \\
\hline Glibenclamide 2.5 & $110.6 \pm 4.2$ & $130.2 \pm 6.4^{* *}$ & $228.4 \pm 4.6^{* *}$ & $114.2 \pm 4.4^{* *}$ \\
\hline VCAE 200 & $108.4 \pm 5.6$ & $236.4 \pm 5.2^{* *}$ & $192.4 \pm 5.0^{* *}$ & $126.4 \pm 5.4^{* *}$ \\
\hline VCAE 400 & $106.8 \pm 6.8$ & $224.4 \pm 5.6^{* *}$ & $186.8 \pm 4.6^{* *}$ & $180.6 \pm 4.6^{* *}$ \\
\hline VCEE 200 & $106.6 \pm 2.4$ & $222.8 \pm 2.4^{* *}$ & $188.6 \pm 4.2^{* *}$ & $142.8 \pm 2.6^{* *}$ \\
\hline VCEE 400 & $108.0 \pm 4.8$ & $224.2 \pm 4.8^{* *}$ & $184.2 \pm 4.4^{* *}$ & $138.2 \pm 4.2^{* *}$ \\
\hline
\end{tabular}

TABLE-2

EFFECT OF AQUEOUS AND ETHANOL EXTRACT OF ROOTS OF Ventilago calyculata Tul. ON ALLOXAN INDUCED DIABETES RATS

\begin{tabular}{|c|c|c|c|}
\hline Group/treatment $(\mathrm{mg} / \mathrm{kg})$ & 0 day $(\mathrm{mg} / \mathrm{dL})$ & After 7 days (mg/dL) & After 15 days $(\mathrm{mg} / \mathrm{dL})$ \\
\hline Normal control & $76.16 \pm 5.36$ & $75.66 \pm 3.94$ & $75.0 \pm 4.96$ \\
\hline Diabetic control & $220.83 \pm 19.0^{*}$ & $214.52 \pm 10.6^{*}$ & $211.33 \pm 20.30^{*}$ \\
\hline Glibenclamide 2.5 & $232.33 \pm 13.9^{* * *}$ & $184.83 \pm 12.8^{* * * *}$ & $129.83 \pm 19.20^{* * * *}$ \\
\hline VCAE 200 & $238.6 \pm 12.8^{* *}$ & $198.22 \pm 16.2^{* *}$ & $172.8 \pm 22.42^{* *}$ \\
\hline VCAE 400 & $236.4 \pm 12.6^{* *}$ & $194.44 \pm 18.6^{* *}$ & $170.4 \pm 20.8^{* * * *}$ \\
\hline VCEE 200 & $242.2 \pm 22.20^{* * *}$ & $198.24 \pm 18.2^{* * * *}$ & $138.68 \pm 12.02^{* * *}$ \\
\hline VCEE 400 & $240.2 \pm 16.8^{* *}$ & $194.8 \pm 16.4^{* *}$ & $134.66 \pm 10.8^{* * * *}$ \\
\hline
\end{tabular}

Values are mean \pm SEM, $\mathrm{n}=6$. (One way ANOVA Followed by Dunnette multiple Comparisons test). Super script $*$, $* *$, $* * *$ denotes statistically significance of $\mathrm{P}<0.05, \mathrm{P}<0.01, \mathrm{P}<0.001$, when compared with respective diabetic control

Oral glucose tolerance test: The oral glucose tolerance test was performed in overnight fasted $(18 \mathrm{~h})$ normal rats and divided into six groups $(n=6)^{4}$.

Group I (normal): Treated with $0.9 \%$ saline solution; Group II (standard): Treated with glibenclamide $(2.5 \mathrm{mg} / \mathrm{kg})$; Group III and IV: Treated with VCAE (200 and $400 \mathrm{mg} / \mathrm{kg}$ ); Group V and VI: Treated with VCEE (200 and $400 \mathrm{mg} / \mathrm{kg}$ );

Glucose $(3 \mathrm{~g} / \mathrm{kg})$ was fed $30 \mathrm{~min}$ after the administration of VCAE and VCEE. The blood samples were collected for the measurement of blood glucose level from the tail vein on 0, 30, 60 and $120 \mathrm{~min}$.

Anti-diabetic study: NIDDM was induced in overnight fasted adult male rats weighing 150-200 g by single interaperitoneal injection of $120 \mathrm{mg} / \mathrm{kg}$ alloxan monohydrate. Hyperglycemia was confirmed by the elevated glucose levels determined at $72 \mathrm{~h}$. Animals with blood glucose level more than $150 \mathrm{mg} / \mathrm{dl}$ were considered as diabetic. Rats found with permanent NIDDM were used for the antidiabetic study ${ }^{5}$ and were divided into seven groups $(n=6)$. The extracts were administered for 15 days.

Group I (normal): Treated with $0.9 \%$ w/v saline solution Group II: Diabetic control rats treated with $0.9 \%$ w/v saline solution; Group III (standard): Treated with glibenclamide (2.5 $\mathrm{mg} / \mathrm{kg}$ ); Group IV and V: Treated with VCAE (200 and 400 $\mathrm{mg} / \mathrm{kg}$ ); Group VI and VII: Treated with VCEE (200 and 400 $\mathrm{mg} / \mathrm{kg}$ ); Blood samples were collected for the measurement of blood glucose level from the tail vein on 0,7 and 15 day. The blood glucose level was determined by digital glucometer (Accu-chek, Roche Diagnostics, India) ${ }^{6}$.

Histological observations: The whole pancreas from each animal was removed after sacrificing the animal and was collected in $10 \%$ formaline solution and immediately processed by the paraffin technique. Sections of 5 micron thickness were cut and stained by haematoxylin and eosin (H \& E) for histological examination.

Statistical analysis: Values are expressed as mean S.E.M. $(n=6)$. Statistical significance was determined by one way analysis of variance (ANOVA) followed by Dunnet's t test. *, $* *, * * *$ denotes statistically significance of $\mathrm{P}<0.05, \mathrm{P}<0.01$, $\mathrm{P}<0.001$, when compared with respective diabetic control.

\section{RESULTS AND DISCUSSION}

Administration of alloxan (120 mg/kg, i.p.) led to 2.5fold elevation of fasting blood glucose levels, which was maintained over a period of 15 days. Fifteen days daily treatment of VCAE and VCEE ((200 and $400 \mathrm{mg} / \mathrm{kg})$ led to a dose dependent fall in blood sugar levels. Vehicle control animals were found to be stable in their blood level (Table-2). Alloxan induced diabetic, which is reversed by VCAE and VCEE (100 and $200 \mathrm{mg} / \mathrm{kg}$ ). Serum cholesterol, serum tryglycerides, serum HDL, serum LDL and VLDL levels were decreased significantly by glibenclamide and VCAE and VCEE (200 and $400 \mathrm{mg} / \mathrm{kg}$ ) (Table-3).

Photomicrographs (Fig. 1) showed normal acini and normal cellular population in the islets of langerhans in pancreas of vehicle-treated rats (a). Extensive damage to the islets of langerhans and reduced dimensions of islets (b), restoration of normal cellular population size of islets with hyperplasia by glibenclamide (c) was also shown. The partial restoration of normal cellular population and enlarged size of cells with hyperplasia was shown by VCAE and VCEE (d, e, f and g).

The alloxan has been observed to cause massive reduction of the $\beta$-cell of langerhans and induce hyperglycemia ${ }^{7}$. In this study we have found that VCAE and VCEE decreased blood glucose in alloxan induced diabetic rats. When VCAE and VCEE were administered to glucose loaded normal rats (OGTT) 


\begin{tabular}{|c|c|c|c|c|c|}
\hline \multirow{3}{*}{$\begin{array}{l}\text { Group/treatment } \\
(\mathrm{mg} / \mathrm{kg})\end{array}$} & \multicolumn{4}{|c|}{$\begin{array}{c}\text { TABLE-3 } \\
\text { EFFECT OF AQUEOUS AND ETHANOL EXTRACTS ROOTS OF Ventilago calyculata Tul. } \\
\text { ON SERUM LIPID PROFILE IN ALLOXAN INDUCED DIABETIC RATS }\end{array}$} & \\
\hline & \multicolumn{5}{|c|}{ Changes (mg/dL) } \\
\hline & TC & TG & HDL-C & LDL-C & VLDL-C \\
\hline Normal control & $80.50 \pm 1.35$ & $70.33 \pm 0.76$ & $37.83 \pm 0.72$ & $41.00 \pm 2.80$ & $18.83 \pm 0.79$ \\
\hline Diabetic control & $134.83 \pm 1.96^{*}$ & $140.00 \pm 1.63^{*}$ & $25.67 \pm 1.16^{*}$ & $93.50 \pm 2.38^{*}$ & $30.33 \pm 1.22^{*}$ \\
\hline Glibenclamide 2.5 & $100.67 \pm 3.83^{* *}$ & $98.50 \pm 2.07^{* *}$ & $38.33 \pm 6.72^{* *}$ & $62.33 \pm 1.44^{* *}$ & $24.67 \pm 0.57^{* *}$ \\
\hline VCAE 200 & $97.28 \pm 4.22^{* *}$ & $96.26 \pm 4.22^{* *}$ & $3526 \pm 4.24^{* *}$ & $68.32 \pm 2.62^{* *}$ & $28.48 \pm 2.46^{* *}$ \\
\hline VCAE 400 & $91.67 \pm 2.38^{* * *}$ & $98.83 \pm 1.70^{* * *}$ & $34.83 \pm 0.94^{* * *}$ & $66.67 \pm 1.82^{* * *}$ & $26.83 \pm 0.60^{* * *}$ \\
\hline VCEE 200 & $96.88 \pm 6.88^{* *}$ & $97.24 \pm 8.00^{* *}$ & $34.63 \pm 0.88^{* *}$ & $68.88 \pm 0.24^{* *}$ & $24.86 \pm 2.88^{* *}$ \\
\hline VCEE 400 & $98.17 \pm 3.27^{* * *}$ & $96.00 \pm 2.59^{* * *}$ & $36.67 \pm 1.26^{* * * *}$ & $64.67 \pm 1.52^{* * *}$ & $27.83 \pm 0.47^{* * *}$ \\
\hline
\end{tabular}

$*$, **, $* * *$ denotes statistically significance of $\mathrm{p}<0.05, \mathrm{p}<0.01, \mathrm{p}<0.001$, when compared with respective diabetic control.



Fig. 1. Histological comparison of the pancreas from (a) normal, (b) diabetic, (c) standard, (d and e) aqueous extract (200 and $400 \mathrm{mg} /$ $\mathrm{kg}$ ), (f and $\mathrm{g}$ ) ethanol extract (200 and $400 \mathrm{mg} / \mathrm{kg}$ ) in alloxan induced diabetic rats

fasted for $18 \mathrm{~h}$, reduction in blood glucose levels was observed after $60 \mathrm{~min}$. The decline reached its maximum at $2 \mathrm{~h}$. In our study, the difference observed between the initial and final fasting blood glucose levels of different groups under investigation revealed a significant elevation in blood glucose in diabetic control group at the end of the 15- day experimental period. Administration of VCAE and VCEE to diabetic rats showed a significant decrease in the fasting blood glucose. The possible mechanism by which VCAE and VCEE may be potentiating the insulin effect of plasma by increasing either the pancreatic secretion of insulin from the $\beta$-cell of islets of langerhans or its release from bound insulin ${ }^{8}$. It has been well established that diabetic mellitus alters the normal metabolism of cholesterol and triglyceride showed an increase in alloxan induced diabetic rats. Under normal conditions, the enzyme lipoprotein lipase hydrolyzes triglycerides. Diabetes mellitus results in failure to activate this enzyme thereby causing hypertriglyceridemia ${ }^{9}$. Administration of VCAE and VCEE decreased cholesterol and triglyceride in diabetic rats.

Flavonoids, steroids, triterpenoids, alkaloids and phenolics compounds are known phytoprinciples ${ }^{10}$ to regenerate the damaged $\beta$-cells in the alloxan induced diabetic rats. The preliminary phytochemical screening of VCAE and VCEE revealed that the presence of various phytoconstituents including alkaloids, phenolic compounds, flavonoids, tannins, etc. Hence, these above pytoconsituents may be responsible for antidiabetic activity.

\section{Conclusion}

It is concluded from the data that roots of Ventilago calyculata possesses significant antidiabetic activity and it may prove to be effective for the treatment of NIDDM. However, longer duration studies on chronic models are necessary to elucidate the exact mechanism of action so as to develop it as a potent antidiabetic drug.

\section{REFERENCES}

1. A.N. Nagappa, P.A. Thakurdesai, N.V. Rao and J. Singh, J. Ethnopharmacol., 88, 45 (2003).

2. C.P. Khare, Indian Medicinal Plant: An Illustrated by Dictionary, Springer, p. 697 (2007).

3. OECD Guideline for Testing of Chemicals 423 [online]. Acute Oral Toxicity. Acute classic method. 17 Dec 2007; 1/4-1/14. Available from: URL: http://iccvam.niehs.nih.gov/SuppDocs/FedDocs/OECD/OECD_ GL423.pdf.

4. A. Shirwaikar, K. Rajendran and R. Barik, J. Ethnopharmacol., 107, 285 (2006).

5. S. Venkatesh, J. Thilagavathi and D. Sundar, Fitoterapia, 79, 79 (2008).

6. S. Jain, G. Bhatia, R. Barik, P. Kumar, A. Jain and V.K. Dixit, J. Ethnopharmacol., 127, 325 (2010).

7. M. Goldner and G. Gomri, Endocrinology, 33, 297 (1943).

8. S.S. Gupta, Ind. J. Pharmacol., 26, 5 (1994).

9. J.W. Anderson, Curr. Atheroscleros. Rep., 2, 536 (2000).

10. M.D. Ivorra, M. Paya and A. Villar, J. Ethnopharmacol., 27, 243 (1989). 